\title{
ESFALECIMENTO DA TRADIÇÃO E RECUSA DA CONCEPÇÃO DIALÉTICA DA HISTÓRIA EM HANNAH ARENDT
}

\author{
Joelson Pereira de SOUSA * \\ * Mestre em Filosofia e Professor na Universidade do Estado da Bahia - UNEB. E-mail: \\ joelson.filo@hotmail.com.
}

Artigo submetido em fevereiro/2015 e aceito em agosto/2015

DOI: http://dx.doi.org/10.15628/dialektike.2015.2793

\begin{abstract}
RESUMO
O objetivo deste trabalho é discutir a recusa da compreensão dialética da história empreendida pela filósofa alemã Hannah Arendt (1906-1975) nas obras Entre o passado e o futuro (1954) e Sobre a violência (1970), destacando, por meio da problematização dos argumentos trazidos pela autora, a crítica da tentativa hegeliana de reconciliação com a realidade através da compreensão do significado mais profundo de todo o processo histórico, a qual Hannah Arendt denomina de filosofia utilitarista que visa impor à
\end{abstract}

realidade o significado e a lei preconcebidos pelo homem. Tal posição da autora favorece uma análise mais aprofundada das relações entre poder e força, política e violência, tão imbricadas na atual condição dos conflitos entre governos e populações que ocorrem ao redor do mundo. Conforme Hannah Arendt, a maior questão a ser enfrentada nestes casos é o fato dos dois lados do conflito encararem a política do ponto de vista da glorificação da violência.

PALAVRAS-CHAVE: Dialética. História. Política. Violência. Hannah Arendt.

\begin{abstract}
The aim of this paper is to discuss the refusal of the dialectical understanding of history undertaken by the German philosopher Hannah Arendt (1906-1975) in the works between the past and the future (1954) and On the violence (1970), especially through the questioning of the arguments brought by the author, the critique of Hegel's attempt at reconciliation with reality by understanding the deeper meaning of the whole historical process, which Hannah Arendt calls the utilitarian philosophy that seeks to impose the
\end{abstract}

reality the meaning and the law preconceived by man. This position of the author favors further analysis of the relationship between power and strength, politics and violence, so intertwined in the current condition of the conflicts between governments and populations that occur around the world. As Hannah Arendt, the major question to be addressed in these cases is the fact that both sides of the conflict envisage the point of view of policy glorification of violence.

KEYWORDS: Dialectic. History. Politics. Violence. Hannah Arendt.

Neste artigo pretendo abordar a identificação entre violência e política no pensamento de Hannah Arendt, a partir das obras Entre o passado e o futuro (1968) e Sobre a violência (1969). Interessa-me pontualmente trabalhar dois argumentos em destaque nestes textos, a saber, o esfacelamento da tradição que evidencia uma ruptura com o pensamento 


\section{SOUSA, Joelson Pereira de (2015)}

político tradicional, e a recusa da concepção dialética da história que nega a possibilidade de reconciliação entre a violência política e a realidade.

\section{PONTO DE PARTIDA}

Ao propor uma reflexão sobre violência e política a filósofa alemã Hannah Arendt observa diretamente a eclosão de inúmeros conflitos armados que se alastraram por toda parte nas décadas de 60 e 70. Em convulsão, o mundo contemporâneo testemunhou guerras, guerrilhas, revoltas, revoluções, ditaduras e totalitarismos de toda sorte, difundindo uma equação capaz de permitir as formas mais cruéis de barbárie, a conjunção entre violência e política.

Já nas primeiras linhas do livro Sobre a Violência (1969) Arendt se refere a este período turbulento como "o pano de fundo do século XX", a pedra de toque da sua abordagem sobre a relação entre poder e violência na cena política do século XX, segundo ela, "um século daquela violência que comumente se acredita ser o seu denominador comum”. (p.17) O momento histórico que consagrou a violência como estratégia política eficiente para a garantia do poder de governar.

Nestas décadas, a corrida armamentista promovida pelas superpotências USA e URSS se tornou o exemplo mais contundente da aceitação desta premissa, lançando as nações mais influentes e desenvolvidas do mundo na busca pela ampliação do seu potencial de destruição, por meio de uma espécie de tecnologia da violência. Tal situação resulta em uma elevação nunca imaginada da potência bélica de forças políticas antagônicas no cenário internacional. O domínio de armas nucleares de destruição em massa, por parte destas superpotências, revela, segundo Arendt, uma mudança significativa no entendimento político do uso da violência, "a corrida armamentista, como não é mais uma preparação para a guerra" (p.18) representa a posse de uma tecnologia bélica de alcance planetário que passaria a ser "a melhor garantia para a paz". Com isso, a justificativa para tal esforço precisa ser ajustada, camufla-se o objetivo de vitória sobre o inimigo com um paradoxo perigoso: legitimar a guerra afirmando o desejo de aniquilá-la. Esse é um argumento que tende a naturalizar a interação violência e política como modus operandi da governabilidade, condicton sine qua non para o estabelecimento da ordem política, onde a violência se configura como a forma básica de manifestação do poder. 


\title{
SOUSA, Joelson Pereira de (2015)
}

Diante desta ambivalência, Arendt conclui pela falta de alternativas para a superação desta fórmula que afirma a guerra como principal força estruturadora na sociedade:

\begin{abstract}
A principal razão em função da qual a guerra ainda está entre nós não é um secreto desejo de morte da espécie humana, nem um instinto irreprimível de agressão ou tampouco e por fim, de forma mais plausível, os sérios perigos econômicos e sociais inerentes ao desarmamento, mas o simples fato de que nenhum substituto para esse arbítrio último nos negócios internacionais apareceu na cena política. $(2010$, p.20)
\end{abstract}

Essa limitação da capacidade de propor novas soluções a problemas tão antigos nas sociedades políticas leva inevitavelmente à incorporação definitiva da violência como elemento essencial à solução de conflitos na esfera pública. Confirmando as palavras de Arendt, nosso tempo parece ter herdado das gerações passadas "a experiência de uma maciça intromissão da violência criminosa, em larga escala, na política” (ARENDT, 2010, p.29). O terror dos campos de extermínio nazista, a tortura legal, os vários genocídios e os massacres em massa de civis são exemplos paradigmáticos dessa intromissão.

Neste sentido, a sentença do antropólogo francês René Girard na obra A violência e o sagrado de 1972, afirmando que "a violência agora é de todos e está em todos", corrobora a posição antecipada por Arendt ao tratar a conjunção entre violência e política, consolidando a relevância da temática em qualquer abordagem que pretenda se ocupar da sociedade humana. Uma questão bem latente em nossos dias, nos quais o uso político da violência aparece cotidianamente nos debates populares, alcançando desde as conversas dos cidadãos comuns até a pauta de intelectuais e instituições que representam a sociedade.

Vale lembrar, que no campo da filosofia política, Arendt já expressava em termos definitivos essa posição central da violência, ao mesmo tempo critica o fato desta temática não ter sido devidamente considerada até então:

Ninguém que se tenha dedicado a pensar a história e a política pode permanecer alheio ao enorme papel que a violência sempre desempenhou nos negócios humanos, e, à primeira vista, é surpreendente que a violência tenha sido raramente escolhida como objeto de consideração especial [...] Isso indica quanto a violência e sua arbitrariedade foram consideradas corriqueiras e, portanto, negligenciadas; ninguém questiona ou examina o que é óbvio para todos. (2010, p.23) 


\section{SOUSA, Joelson Pereira de (2015)}

No campo prático, observam-se cada vez mais as pessoas se armando e cercando suas casas, comunidades fazendo passeatas pedindo paz, grupos armados que se proliferam, radicais promovendo o terror, países que mobilizam suas forças de guerra, governos que implementam programas de combate à criminalidade etc. ${ }^{1}$ Torna-se inegável o fato de que o tema da violência passa a fazer parte da agenda diária de muitos organismos e grupos, levando a Organização das Nações Unidas a proclamar o interstício de 2000 a 2010 como a década em favor de uma cultura de paz, pois a superação da violência é o grande desafio da atualidade e um problema de difícil solução.

Por mais que se note o crescimento da relevância desta temática, não há consenso quanto às causas que a produzem, nem mesmo quanto ao fenômeno da violência em si e, muito menos, quanto à sua identificação com a política. Na verdade, desde os primeiros esforços reflexivos sobre este tema, com o pensador francês Georges Sorel e suas Reflexões sobre a violência (1908) até nossos dias "os problemas da violência ainda permanecem obscuros". ${ }^{2}$ Permitindo-nos pensar que a explicação tanto do fenômeno como das causas da violência, e ainda sua aproximação com a política, seja, até este momento, uma tarefa a se realizar.

Por tais motivos, se tomarmos o contexto atual de um mundo conturbado politicamente, ocupado por potências bélicas e transpassado pelas ameaças de terror, veremos a urgência de um aprofundamento das posições assumidas por Arendt, apoiado, sobretudo, no diagnóstico de nosso tempo como um período histórico de obscurecimento das condições políticas democráticas. Pois onde a política não foi reduzida ao plano da violência, como no caso dos regimes totalitários, foi reduzida ao plano da administração burocrática dos interesses econômicos. (DUARTE, 2002)

Frente a essa questão, proponho analisar dois argumentos manuseados por Hannah Arendt ao confrontar o pensamento político da tradição com a real conjunção entre violência e política, que ela conheceu tão de perto por meio da truculência do regime nazista. $\mathrm{O}$ primeiro é o argumento do esfacelamento da tradição e o segundo é a recusa da concepção dialética da história, ambos apresentados nos ensaios "A tradição e a época moderna" e "O conceito de história antigo e moderno" que integram o livro Entre o passado e o futuro de 1968, sendo estes argumentos retomados e desenvolvidos na obra Sobre a violência de 1969.

\footnotetext{
${ }^{1}$ Vejamos os recentes enfrentamentos entre o Estado e o crime organizado no Rio de Janeiro e em São Paulo, exemplos do uso da violência com a finalidade de extingui-la.

${ }^{2}$ Apud AREDNT, Hannah. Sobre a Violência. Rio de Janeiro: Civilização Brasileira, 2010. p. 51

Dialektiké. Ano 2, v. 2, out 2015, p. 118-130 | Revista de Filosofia 


\section{O ESFACELAMENTO DA TRADIÇÃO}

A ideia chave que abre o ensaio “A tradição e a época moderna” In: Entre o passado e o futuro (1968) é que a tradição de nosso pensamento político teria início e fim bem definidos. Como se Arendt percebesse claramente o esgotamento de um modo já calcificado de conceber as relações políticas: "A tradição de nosso pensamento político teve seu início definido nos ensinamentos de Platão e Aristóteles. Creio que ela chegou a um fim não menos definido com as teorias de Karl Marx.” (2011, p.43)

Desde as revoluções que inauguraram a Idade Moderna já se percebia que o mundo estava sendo invadido por inovações que resultaram no aparecimento de novos problemas com os quais a tradição do pensamento político era incapaz de lidar. Para Arendt, pensadores como Kierkegaard, Marx e Nietzsche, precedidos por Hegel, situam-se no final dessa tradição.

Hegel foi o primeiro a conceber a História como uma totalidade, sendo movida pelo desenvolvimento de um fluxo contínuo capaz de delinear o elo comum entre as mais diversas manifestações do passado. Trata-se de um idealismo nas alturas, responsável por criar uma harmonia entre as posições contrárias e ambivalentes que se confrontaram em todo o percurso da História, suplantando assim, todos os sistemas forjados anteriormente na tradição. Com isso, segundo Arendt, Hegel consegue estabelecer "o fio da continuidade histórica" que tornaria desnecessário qualquer apego à autoridade da tradição.

Kierkegaard, Marx e Nietzsche, cada um com seu modo e intensidade, desenvolveram essa posição hegeliana questionando os conceitos tradicionalmente aceitos na história da filosofia, e assim, colaboraram decisivamente para o abalo da autoridade do passado. Estes pensadores buscavam algo novo, pois entendiam a necessidade de novas ideias para dar conta dos fenômenos da modernidade. Romperam com a autoridade da tradição, embora continuassem influenciados pelo quadro de sua referência. Segundo Arendt é como se "tentasse desesperadamente pensar contra a tradição, utilizando ao mesmo tempo suas próprias ferramentas conceituais". (2011, p.52) Isso por que "O fim da tradição não significa necessariamente que os conceitos tradicionais tenham perdido seu poder sobre as mentes dos homens". (p.53) 


\section{SOUSA, Joelson Pereira de (2015)}

Vejamos alguns pontos destacados por Arendt do embate conceitual que Kierkegaard, Marx e Nietzsche travaram com a tradição:

1) "O salto de Kierkegaard, da dúvida para a crença consistiu em uma inversão e distorção da relação tradicional entre razão e fé." (p.56)

Enquanto a tradição teológica, tanto da patrística quanto da escolástica, buscava promover uma relação de cooperação entre fé e razão, sob o lema de crer para compreender na patrística e o compreender para crer, na escolástica. Kierkegaard não pensa a partir deste princípio teológico que aproxima a fé da razão, seu ponto de partida é a introdução da dúvida cartesiana na crença religiosa. Ao propor o salto da dúvida para a crença, ele inverteu e distorceu a relação tradicional entre fé e razão, afirmando que o homem não pode confiar na capacidade de sua razão ou de seus sentidos para receber a verdade. Jamais a razão poderia confirmar ou conduzir à crença como queria o pensamento teológico tradicional, para Kierkegaard, somente a dúvida aproxima da crença e a fé é um salto no escuro.

2) "O salto de Marx da teoria para a ação, e da contemplação para o trabalho..." (p.56)

$\mathrm{Na}$ história do pensamento filosófico tradicionalmente se buscou refletir sobre os valores que devem governar as relações humanas na vida pública, tal reflexão na história da filosofia resultou em um discurso meramente contemplativo e utópico, quando muito, em uma teoria política legitimadora das formas de poder já estabelecidos. Marx, então, desafia toda a tradição do pensamento político e filosófico, ao descer ao chão o idealismo hegeliano, propondo uma análise materialista da história. Consequentemente, a filosofia é superada pela política, a teoria é superada pela ação e a contemplação é superada pelo trabalho.

A incompatibilidade entre o pensamento político clássico e as modernas condições políticas destacadas por Marx, resultou do fato das revoluções francesa e industrial elevarem a realidade do trabalho. Antes desprezado como atividade de segundo nível, agora coroado como autorealização da sociedade humana. Centrado nas condições matérias e na questão do trabalho como determinantes da existência humana, Marx revira a razão política contemplativa e o movimento dialético do espírito em Hegel, materializando as ideias nas lutas de classes. 


\section{SOUSA, Joelson Pereira de (2015)}

3) "O salto de Nietzsche do não-sensual reino transcendente e não-sensível das ideias e da medida para a sensualidade da vida..." (p.56)

A tradição do pensamento filosófico desde os gregos até sua cristianização reduziu a vida sensual do corpo a mero adereço da condição espiritual humana, promovendo um tipo de moral com valores expressamente contrários à vida e ao homem. Nietzsche se opõe a essa razão que desumaniza o homem, e com o seu platonismo invertido, sua insistência na vida e no dado sensível e material, caminha em direção a uma transvaloração dos valores morais, buscando o mundo verdadeiro no qual reside a verdadeira vontade e a verdadeira potência humana. Não há mais dualismos que orientam o pensar e o agir, o valor máximo é o valor da dignidade da própria vida. A transvaloração dos valores surge da incompatibilidade entre com as "ideias" tradicionais. Com isso, tem-se uma superação da metafísica tradicional com seus meros conceitos sem correspondência com a experiência humana válida, afirma-se aqui a libertação da tradição.

Nas palavras de Arendt podemos resumir assim esse confronto filosófico que levou ao esfacelamento da tradição:

O que Kierkegaard queria era afirmar a dignidade da fé contra a razão [...], assim como Marx desejava reafirmar a dignidade da ação humana contra a contemplação [...], e Nietzsche, a dignidade da vida humana contra a impotência do homem moderno. (p.58)

Essas rebeliões realizadas de forma consciente foram importantes porque levaram em conta traços da modernidade incompatíveis com a tradição, além disso, serviu para decretar a ruína da autoridade da tradição no século XX, mediante as suspeitas levantadas por Kierkegaard, Marx e Nietzsche.

No entanto, o foco de Arendt agora vira-se para a questão da violência, uma temática que também nunca encontrou ecos na tradição do pensamento político, corroborando a ideia de que a tradição mais uma vez se mostra insuficiente para analisar uma realidade tão difundida no presente, a saber, a conjunção entre violência e política. Na obra Sobre a violência (1969) ela destaca que "Quem quer que tenha procurado alguma forma de sentido nos registros do passado viu-se quase obrigado a enxergar a violência como um fenômeno marginal" (2010, p.23).

Kierkegaard, Marx e Nietzsche têm em comum no embate contra a tradição a superação do conceito filosófico de homem como animal racional. Kierkegaard quer afirmar o 


\section{SOUSA, Joelson Pereira de (2015)}

homem angustiado; Marx, o homem enquanto força produtiva e Nietzsche, o homem como vontade e vontade de potência. Esses ataques à autoridade da tradição foram os responsáveis por abrir caminho para um modo de pensar que não dispensava a legitimidade do passado ou da herança cultural dos homens. Por sua vez, Arendt, ao aceitar essa ruptura com a tradição consumada nestes pensadores, parte desta mesma conclusão quando analisa que "Hoje todas essas antigas verdades sobre a relação entre guerra e política, ou a respeito da violência e do poder, tornaram-se inaplicáveis" (2010, p.24)

Com isso, o argumento do esfacelamento da tradição que norteia o ensaio "A tradição e a época moderna" no livro Entre o passado e o futuro (1968) realiza uma espécie de epoché menos radical, pois não destrói a tradição, mas a desconsidera ao abrir caminho para uma forma de pensar descompromissada com o legado histórico da tradição, até por que, no caso de Arendt, as categorias tradicionais do pensamento político não contemplavam a relação entre violência e política como uma questão central. Na obra Sobre a violência (1969), Arendt então, abordará sobre o caráter político da violência tendo em mente o silêncio da tradição sobre este tema, considerando a percepção de que certas tendências do presente não mais podiam ser compreendidas dentro do quadro de referências da tradição. A violência política surge quando as crenças que lastreiam o poder estão sendo perdidas.

\section{A RECUSA DA CONCEPÇÃO DIALÉTICA DA HISTÓRIA}

Essas reviravoltas que levaram à ruína a autoridade da tradição põem em foco um princípio de sentidos ambivalentes. A afirmação de um dos opostos - fé versus intelecto (Kierkegaard); prática versus teoria (Marx); vida sensível versus verdade supra-sensível (Nietzsche) - traz necessariamente à luz o seu oposto rejeitado, fazendo com que um, só tenha sentido diante de sua oposição. Tal princípio que se articula na reflexão desses pensadores, resulta da concepção dialética da história que Hegel estabeleceu de forma universalmente válida. Segundo Arendt:

Kierkegaard, Marx e Nietzsche permaneceram hegelianos na medida em que viram a História da Filosofia passada como um todo dialeticamente desenvolvido; seu grande mérito está em que radicalizaram essa nova abordagem ao passado da única maneira em que ela podia ser ainda desenvolvida, isto é, questionando a tradicional hierarquia conceitual que dominara a Filosofia Ocidental desde Platão e que Hegel dera ainda por assegurada. (2011, p.55-56) 


\section{SOUSA, Joelson Pereira de (2015)}

Para Hegel, a tradição se realiza por meio de um movimento dialético que encontra a verdade na tensão das oposições que se revelam no processo temporal, no qual o curso da história estabelece os antagonismos nos quais se move. Movimento que não é aleatório, mas pelo contrário, marcha dialeticamente em direção à liberdade do espírito, revelando o sentido teleológico da concepção hegeliana da História. Sentido que permite aos valores mais divergentes, mais contraditórios e as autoridades mais conflitantes, serem reduzidos a um desenvolvimento unilinear e dialeticamente coerente. Segundo Arendt, "Hegel, finalmente, em um derradeiro e gigantesco esforço, reuniu em um todo coerente e em autodesenvolvimento as diversas tendências da Filosofia tradicional [...]” (2011, p.66)

Essa concepção hegeliana da História como movimento dialético unificador dos opostos, identificada por meio da tríade tese, antítese e síntese, foi amplamente aceita e pouco questionada, pois permitia o desenvolvimento da ideia de uma História universal, capaz de absorver as mais absurdas contradições em nome de um processo contínuo de avanço histórico.

Hegel pretendia que a descoberta do movimento dialético como uma lei universal, governando ao mesmo tempo os negócios humanos (a história) e a razão interna dos eventos naturais, demostrasse a identidade entre matéria e pensamento. (ARENDT, 2011, p.66).

A partir de Hegel nenhuma oposição seria maior que o movimento dialético, todas as contradições históricas poderiam ser conciliadas em uma História universal. Bem a seu modo, Karl Marx seria um dos autores que mais tiraram proveito desta posição. No ensaio "O conceito de História - antigo e moderno" In: Entre o passado e o futuro (1968), Arendt considera que

Marx tomou o significado hegeliano de toda a história, o progressivo desdobramento e realização da ideia de liberdade, como sendo um fim da ação humana, e quando, além disso, em conformidade com a tradição, considerou esse 'fim' último como o produto final de um processo de fabricação. (2011, p.113)

Ele também manteve o sentido de finalidade do processo histórico, que Hegel também havia expressado. No entanto, vai além de Hegel, quando percebe a história como resultado do fazer humano e, por isso, possuidora de um início e de um fim, sendo possível determinar não só a forma de seu movimento (o movimento dialético), mas também o seu conteúdo (a luta de 


\section{SOUSA, Joelson Pereira de (2015)}

classes). É justamente neste ponto que reside o cerne da reviravolta marxista, o que impulsiona o movimento dialético não é o espírito da humanidade como afirmava o idealismo de Hegel, mas sim as condições materiais que sempre na história resultou na luta de classes. Segundo Arendt, “... para Marx essa fórmula parecia desvendar todos os segredos da história, exatamente como a lei da gravidade parecera desvendar todos os segredos da natureza". (2011, p.115).

Diante de tantas certezas fundamentadas nesta noção de história como processo dialético unificador, Arendt, preocupada em pensar a relação entre violência e política, não aceita essa reconciliação do homem com a realidade e recusa a concepção dialética da história, mesmo sendo um paradigma consagrado e já incorporado à maior parte das análises políticas em seu tempo.

Vou destacar dois aspectos que encorparam essa recusa arendtiana da concepção dialética da história:

O primeiro é o da possibilidade de harmonização, consequência inevitável de uma dialética capaz de unificar as práticas mais contraditórias e os valores mais ambivalentes em nome de um progresso ininterrupto da história. Segundo Arendt, por intermédio desta possibilidade de harmonização,

....a avassaladora massa dos valores mais divergentes, dos mais contraditórios pensamentos e das mais conflitantes autoridades [...] foram reduzidos a um desenvolvimento unilinear e dialeticamente coerente [...] (2011, p. 55).

Essa forma harmonizadora de conceber o desenvolvimento da história implica na legitimação da lógica absurda de fazer uma guerra para acabar com todas as guerras ou então, de modo mais paradoxal ainda, dizer que necessariamente a paz e guerra caminham juntas na História, garantindo o progresso da humanidade.

Na obra Sobre a violência (1969), Arendt retoma esse ponto da sua recusa à concepção dialética da história, afirmando que

A ideia de Marx, tomada de empréstimo a Hegel, de que cada velha sociedade traz consigo as sementes da sua sucessora, do mesmo modo como todo organismo vivo traz consigo as sementes de sua descendência, é realmente não apenas a mais engenhosa, como também a única garantia conceitual possível para a eterna continuidade do progresso da história; e posto que o movimento desse progresso de advir do confronto de forças 
antagônicas, é possível interpretar cada 'retrocesso' como um recuo necessário, mas apenas temporário. (2010, p.43)

Seria bom, se não fosse trágico. Pois essa fórmula do desenvolvimento histórico, impulsionado por conflitos e antagonismos, esconde uma perniciosa lógica legitimadora da violência, na qual o mal seria necessário para criar o bem. Isso explicaria a grande confiança de Hegel e Marx no poder da dialética, em virtude da qual os opostos não se destroem, mas se desenvolvem suavemente, transformando-se um no outro, pois as contradições promovem o desenvolvimento e não o paralisam - o mal não é mais do que o modus privativo do bem, que o bem pode advir do mal - em síntese, o mal é apenas a manifestação temporária de um bem ainda oculto. (ARENDT, 2010, p.80)

Na obra Origens do totalitarismo (1951), Arendt já indicava a recusa desta possibilidade de harmonização conciliadora da história, ela percebeu que a violência não poderia reconstruir dialeticamente a paz. Depois de Auschwitz, entendido como o mal radical, já não havia mais como sustentar a noção de gradual desenvolvimento e transformação de valores ao longo do progresso da história. Hoje nada parece mais discutível que a ideia de que o curso da história esteja dirigido à crescente realização da liberdade.

O segundo aspecto que pode ser apontado na recusa arendtiana da concepção dialética da história é a referência ao uso notadamente instrumental da dialética, tanto na teoria marxista como em seus seguidores. Segundo Arendt, esta instrumentalização é típica

[...] de todas as filosofias estritamente utilitaristas tão comuns e características da primeira fase industrial da época moderna, quando os homens, fascinados pelas novas possibilidades de manufaturar, pensavam todas as coisas em termos de meios e fins, isto é, categorias cuja validade obtinha sua origem e justificação na experiência de produção de objetos-deuso. (ARENDT, 2011, p.115)

Neste sentido instrumental, o uso da concepção dialética no conjunto das teorias históricas resultou na legitimação da violência como prática política justificável, pois permitiu sua incorporação definitiva nos processos de desenvolvimento histórico. Marx foi o principal pensador que viu na glorificação da violência um padrão passível de determinação da ação política, em nome do qual, governos se impuseram e revoluções se insuflaram, fazendo da violência legítima a regra de ouro da política na modernidade. Tal posição revela um utilitarismo pragmático que coloca a violência integralmente no modo humano de fazer a 


\section{SOUSA, Joelson Pereira de (2015)}

história, impondo à realidade um significado preconcebido, capaz de absorver a tese revolucionária de que o poder brota do cano de uma arma.

\section{CONSIDERAÇÕES FINAIS}

Hoje em dia, a maneira hegeliana e marxista de reconciliação das práticas políticas com a realidade, através da compreensão do significado profundo de todo o processo histórico, parece completamente refutada. Pois a violência foi alçada aos patamares mais elevados das estratégias políticas, resultando no aparecimento daquilo que Arendt chama de mal radical jamais visto, a saber, a banalidade do mal das fábricas de morte do nazismo. Não sendo possível, a partir desta experiência, a harmonização desta forma absoluta de violência com o progresso da história, e mesmo se chegasse a uma glorificação ou justificação da violência como tal, esta já não seria política, mas, antipolítica.

Portanto, diferente da concepção dialética hegeliano-marxista de que os opostos não se destroem, mas se superam, a oposição entre violência e política não tende a uma superação, na forma de um bem oculto, mas à degeneração, resultando na destruição do poder e na revelação de um mal ainda maior que a violência: a instalação o terror.

Finalizo lembrando que a originalidade da perspectiva teórica inaugurada por Arendt traduz-se nas críticas às difíceis condições para o exercício da política na atual democracia. Em nossos dias, práticas que minimizam a participação livre dos indivíduos nas questões públicas foram consolidadas, ao mesmo tempo em que, introduziu instrumentos de violência para a conquista e preservação do poder de governar.

\section{REFERÊNCIAS}

ARENDT, Hannah. A Promessa da Política. 1ª ed. Rio de Janeiro: Difel, 2008.

Entre o Passado e o Futuro. 6a ed. São Paulo: Perspectiva, 2007.

. Sobre a Violência. $1^{\mathrm{a}}$ ed. Rio de Janeiro: Civilização Brasileira, 2010.

. Origens do Totalitarismo: anti-semitismo, imperialismo e totalitarismo. Trad. Roberto Raposo. São Paulo: Companhia das Letras, 1990.

A Condição Humana. Trad. Roberto Raposo. 10.ed. Rio de Janeiro: Forense Universitária, 2005. 
BIGNOTTO, N. 'Totalitarismo e liberdade no pensamento de Hannah Arendt'. In: MORAES, E. J. \& BIGNOTTO, N. (orgs.). Hannah Arendt: diálogos, reflexões, memórias. Belo Horizonte: UFMG, 2001.

DUARTE, André. O Pensamento à Sombra da Ruptura: Política e Filosofia em Hannah Arendt. $1^{\text {a }}$ ed. São Paulo: Paz e Terra, 2000.

'Hannah Arendt e a modernidade: esquecimento e redescoberta da política'. In: CORREIA, A. (org.). Transpondo o abismo: Hannah Arendt entre a Filosofia e a política. Rio de Janeiro: Forense Universitária, 2002.

GIRARD, René. A violência e o sagrado. São Paulo: Paz e Terra, 1990.

LAFER, C.: A Reconstrução dos Direitos Humanos: um diálogo com o pensamento de Hannah Arendt. São Paulo, Companhia das Letras, 1988.

Hannah Arendt: pensamento, persuasão e poder. Rio de Janeiro: Paz e Terra, 1979. 